\title{
Oral Insulin Therapy for Diabetic Treatment
}

\section{Tejraj M Aminabhavi*}

Department of Pharmaceutical Engineering and Chemistry, Soniya College of Pharmacy, Dharwad, India

Diabetes has been a deadly disease has been recognized for more than 2,000 years as a deadly and devastating disease. In modern days, due to life style changes coupled with fast and junk food habits, sedentary life, it has become a chronic disease. If not controlled properly, diabetes can be one of the major causes of premature illness and death worldwide due to the disorder of glucose regulation in the human system.

Insulin, a hormone produced in beta-cells of the pancreas, plays an important and key role in maintaining body's metabolism. Though its treatment in the ancient days was not effective, but in modern era, due to the availability of sophisticated test methods of monitoring glucose levels in addition to other clinical tests, doctors are finding it easy to control this disease and its occurrence.

Diabetes is spreading more rapidly in Asian countries than other places in the world. It has been estimated that diabetes rate in Asian countries will go very high by about 2030, with India and China put together accounting for approximately 150 million people. If this is the situation, what measures are needed to circumvent this serious and pandemic problem to lead a healthy and quality life? -How do we artificially supply insulin to the patients? These are some of the major concerns of the medical fraternity.

Insulin was first discovered in 1922 by the Nobel Laureate Frederick Banting, which is most vital for converting glucose into energy. In the absence of insulin, blood glucose level rises to dangerously high, which is termed hyperglycemia, possibly resulting in death of the patients. Too much insulin causes abnormally low glucose levels, called hypoglycemia, is also quite dangerous, and sometimes can be more fatal. For a normal person, the built-in feedback mechanism regulates the secretion of insulin to prevent both the hypoglycemic and hyperglycemic conditions.

Diabetes can be two types: For Type 1, in order to maintain body's blood glucose level, the patients require direct insulin injections as in such persons, the pancreas no longer produces insulin and is ineffective. With Type 2 diabetic patients, the blood glucose levels can be controlled to some extent through oral tablets. Innumerable products are available in the pharma market today and these are not the same as insulin, but they work in different ways to lower the blood glucose levels by stimulating the pancreas to produce more insulin or by helping the body to use insulin efficiently that it produces more effectively.

\section{Oral Insulin Therapy-will it be a Realty?}

As per medical science, oral diabetic tablets could produce more side effects and so, scientists are now developing oral insulin pills based on nanotechnology that are alternative to insulin injections. Tremendous research efforts around the globe are happening to develop oral insulin formulations in the form of nanocapsules consisting of polymers and polymeric hydrogels. Some of these are made of natural polymers bringing the chance of oral insulin delivery ever closer. This nanotechnology basis appears to be the key to success of ensuring protection of insulin when taken orally as a pill, as these delivery devices protect insulin from the degradation due to enzymes in the acidic stomach conditions.
The development of oral insulin capsules is not an easy task due to the inability of potential oral insulin delivery systems to make it through the digestive system unaffected, which is designed to break proteins into amino acids, in order to prevent the absorption of dangerous forms of protein. Part of this process includes maintaining acidic environment of the stomach, which will destroy or break down all of the peptides. Since oral insulin is a type of protein that contains complex peptide bonds,acidic conditions of the stomach break down oral insulin before it goes to the liver.

\section{New Research Findings}

Innumerable research efforts are being done to develop $\mathrm{pH}$ sensitive hydrogels, a three-dimensional network polymer structure that resembles those of the natural body tissues or cells that would encapsulate insulin in its cage structure and release the insulin through swelling and de-swelling mechanisms into the intestine. Such systems formulated to meet the specific needs of oral insulin therapy do not swell in acidic environment of the stomach, but swell in alkaline intestinal condition to release the insulin. Even though these systems have not gained a widespread prominence as yet, oral insulin formulation is still a reality and this would replace completely insulin injections that are often not accepted by the patients.

Researchers around the world are now developing innumerable nanodelivery systems comprising polymers that are biocompatible and biodegradable. Our own research efforts as well as those from other research teams are pushing a significant step forward towards this goal (see for example our two review papers published in this area: K. Chaturvedi, K. Ganguly, M.N. Nadagouda, T.M. Aminabhavi, "Polymeric Hydrogels for Oral Insulin Delivery", J. Controlled Release, 165 (2013) 129-138 and another review, V. Ramesh Babu, P. Patel, R.C. Mundargi, V. Rangaswamy and T.M. Aminabhavi, "Developments in Polymeric Devices for Oral Insulin Delivery", Expert Opinion on Drug Delivery, 5 (2008) 403-415. We can also have published two research papers in this area: R.C. Mundargi, V. Rangaswamy and T.M. Aminabhavi, "Poly ( $n$-vinylcaprolactam-co-methacrylic acid) hydrogel microparticles for oral insulin delivery". J. Microencapsulation, 28 (2011) 384-394 and R.C. Mundargi, V. Rangaswamy and T.M. Aminabhavi, " $\mathrm{pH}$-sensitive oral insulin delivery systems using Eudragit microspheres", Drug Development and Industrial Pharmacy, 37 (2011) 977-985.

There are still many more reports in the literature offering hope to

*Corresponding author: Tejraj M Aminabhavi, Department of Pharmaceutical Engineering and Chemistry, Soniya College of Pharmacy, Dharwad, India, Tel: +91836244854; E-mail: aminabhavit@gmail.com

Received November 01, 2014; Accepted November 10, 2014; Published November 13, 2014

Citation: Aminabhavi TM (2014) Oral Insulin Therapy for Diabetic Treatment. J Pharma Care Health Sys 1: e114. doi:10.4172/jpchs.1000e114

Copyright: ( 2014 Aminabhavi TM. This is an open-access article distributed under the terms of the Creative Commons Attribution License, which permits unrestricted use, distribution, and reproduction in any medium, provided the original author and source are credited. 
the patients affected with diabetes. Oral insulin therapy if developed successful could make a big difference to the lives of people with diabetes! Children, elderly people and those with a phobia of needles would also be benefitted, when the insulin capsules are available in the market.

As of now, several companies across the globe are working with the creation of effective oral insulin delivery systems as well as many major pharmaceutical companies are at the forefront of research and development stage. It is something of a holy grail of medical innovation!. An oral form of insulin would make insulin therapy less complicated, and surely increase the rate at which insulin users comply with their insulin therapy schedule.

Despite many efforts of the scientists around the globe in developing nanotechnology methods, yet no forms of oral insulin pills are available in the open market. Efforts are still continuing at a rapid pace that will one-day may become a reality. 